\title{
A Descriptive Study of Malnutrition in Traumatic Brain Injury Patients
}

\author{
Lauren M Ford ${ }^{1} \odot$, John R Ouma ${ }^{2} \odot$
}

\begin{abstract}
Background: Traumatic brain injury (TBI) patients are commonly faced with excessive muscle wasting and severe malnutrition, despite adequate calories. Malnutrition in TBI patients is associated with adverse outcomes, but the specific factors contributing to this are unknown. Certain factors are associated with a higher risk of malnutrition. Factors looked at in this study are age, sex, race, body mass index (BMI), preexisting comorbidities, surgical intervention, when feeds were started, and what feeds were given.

Methods: Data of the TBI patients were collected prospectively from 2nd June 2019 to 8th November 2019 at the Chris Hani Baragwanath Academic Hospital in Soweto, Gauteng.

Results: A total of 32 patients were included in the study; two were left out due to lack of consent. About $96.88 \%$ of the patients were male, with most patients falling into the age categories of $18-40$ years. A minority of patients were mild TBI, with a GCS of $13-15,4.17 \%$. Of the patients included, the majority was severe TBI, GCS 3-8, 62.5\%. Treatment options for the TBI were split evenly for conservative treatment and surgery. Unfortunately, $25 \%$ of the patients were demised during this study.

The mechanism of injury varied among patients. Fourteen patients were allegedly assaulted, four were involved in pedestrian vehicle accidents (PVA), and eight patients had unknown mechanisms of injury.

The prevalence of malnutrition on day 10 of the mid-upper arm circumference (MUAC) measurement was $31.25 \%$, and on day 21 , it was $56.25 \%$. The only two factors we found to have a risk for malnutrition in TBI was a longer length of hospital stay, $p$-value $<0.001$, and the later feeds were started on the TBI patients, $p$-value 0.014 .

Conclusion: TBI is associated with malnutrition at day 10 postinjury as indicated by a reducing MUAC. Delay to initiation of feeding and shorter hospital stay appear to be independent risk factors for malnutrition post-TBI. Further studies are needed to validate this finding.

Keywords: Malnutrition, Neurosurgery, Neurotrauma, Traumatic brain injury.

Panamerican Journal of Trauma, Critical Care \& Emergency Surgery (2021): 10.5005/jp-journals-10030-1359
\end{abstract}

\section{INTRODUCTION}

While treating patients with traumatic brain injury (TBI), we often face excessive muscle wasting and severe malnutrition, despite adequate caloric supplementation. This malnutrition negatively affects outcomes, yet we do not fully understand its pathophysiology and the factors influencing it.

\section{Traumatic Brain Injury}

Post-traumatic injuries, commonly referred to as $\mathrm{TBI}^{1}$ are injuries caused by forces to the head and can be either external forces or acceleration-deceleration injuries. TBI involves an insult to the brain, direct or indirect, which results in permanent damage to the tissues and blood vessels. It can be blunt or penetrating in nature. An open head injury occurs when an object penetrates the skull and breaks the dura mater, the outermost membrane. In contrast, a closed head injury is also known as "blunt" or "nonpenetrating." ${ }^{2}$ Regardless of the type of injury, all TBls affect all the normal bodily functions. ${ }^{2}$

Functional classification of primary diffuse TBI is based on the best GCS after resuscitation and has prognostic significance. ${ }^{3}$

See Table 1 for GCS grading of TBI.

The leading cause of death in children and young adults in South Africa is trauma, with a mortality rate of five times the global average from motor vehicle collisions and four times the global average of interpersonal violence. ${ }^{4}$ The incidence of TBI in Sub-Saharan Africa is 150-170/100,000 compared with a global average of 106/100,000. ${ }^{4}$ Statistics from 1991 show 316 brain injuries per 100,000 per year in South Africa. ${ }^{5}$ Due to the significant burden

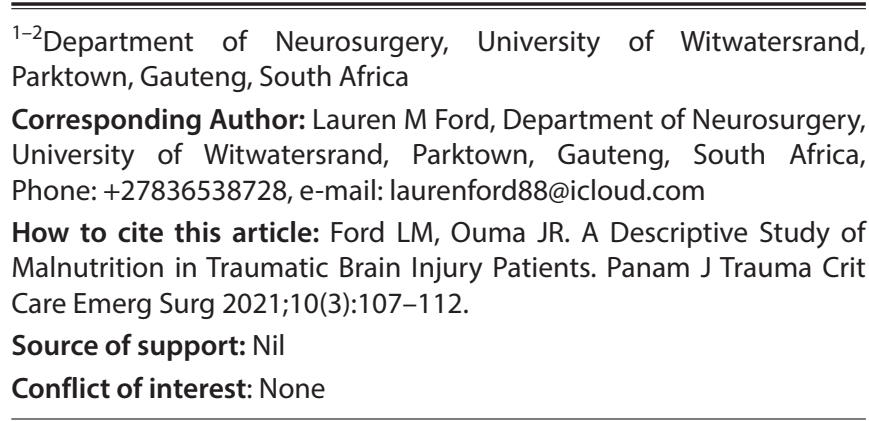

of disease in South Africa, we must understand all aspects of TBI and approach it holistically.

\section{Nutrition}

The World Health Organization (WHO) defines nutrition as the intake of food in relation to the body's dietary needs: however, if the body's nutritional needs are not met, either overnourishment or undernourishment/malnutrition develops. ${ }^{6}$

Malnutrition is defined as a body mass index (BMI) of $<18.5 \mathrm{~kg} / \mathrm{m}^{2}$, or unintentional weight loss (mandatory) with an associated reduction in BMI or a low-fat free mass index (FFMI). Weight loss can be defined as either $>10 \%$ of habitual weight loss over an indefinite period or $>5 \%$ over 3 months. ${ }^{7}$ An all-encompassing definition for malnutrition is "a decline in lean body mass with the potential for functional impairment." ${ }^{8}$ Malnutrition presents 
a substantial socioeconomic challenge in today's healthcare landscape, with an estimated prevalence of $30-50 \% .{ }^{9}$

Nutrition therapy must be initiated to prevent malnutrition. Nutritional therapy is defined as the supply of nutrition or nutrients either orally (regular diet, therapeutic diet, for example, fortified food, oral nutritional supplements) or via enteral nutrition or parenteral nutrition. ${ }^{10}$

In addition to the apparent effects of malnutrition, reduction in weight, loss of fat, and muscle wasting, it also results in severe impairment of muscle function, leading to reductions in respiratory drive, respiratory muscle weakness, and therefore ventilator dependence. Undernutrition can also affect the cardiovascular system, decreasing heart rate, arterial and venous pressures, stroke volume, and cardiac output. In addition, protein deficiency has been associated with poor wound healing, diminished mobility, and a high incidence of bedsores. ${ }^{11}$

\section{Malnutrition in Traumatic Brain Injury}

The complex interaction of the body with nutritional support is exaggerated during illness, particularly after severe TBI. ${ }^{12}$ According to the Guidelines for the Management of Severe Traumatic Brain Injury, a head-injured patient needs at least $140 \%$ of typical metabolic expenditure due to increased metabolic rate and protein catabolism. ${ }^{12}$ Among patients with TBI in ICU, 75\% show clinical markers of malnutrition at 3 weeks. ${ }^{13}$ Malnutrition is more common among TBI patients with poorer GCS scores, which is associated with poorer prognoses and lower survival rates. ${ }^{14}$

Furthermore, lower GCS, total protein, and albumin serum levels on admission are associated with a more significant influence on the development of clinical features of malnutrition.

$\mathrm{BMI}$ is used as an objective indicator of generalized body adiposity, and it is the most widely used anthropometric indicator for clinically assessing the nutritional status of adults. ${ }^{15}$ There is a strong association between BMI and mid-upper arm circumference (MUAC), and it was found easier to perform than weighing in the Sudanese population and correlated very well with BMI for screening of undernourished adults. ${ }^{15}$ In addition, MUAC is very simple to use and is emerging as a useful measure of nutritional status due partly to its applicability in nearly all acutely ill patients whose weight and height measurements may be inappropriate or impossible. ${ }^{15}$

The prevalence of hospital malnutrition is higher in older patients, patients with multiple comorbidities, nonmanual workers, and prolonged hospital stays. ${ }^{16}$ Severe TBIs will also have a higher risk for malnutrition due to nutritional deficits from drowsiness, swallowing difficulties or dysphagia, and confusion. Malnutrition is associated with higher infection and complication rates, extended length of hospital stay, and increased morbidity and mortality. ${ }^{17}$ Additionally, early nutrition (defined as feeding within the first 5 to 7 days postinjury) reduced 2-week mortality in patients with severe TBl; additionally, the amount of nutrition was inversely correlated with mortality. ${ }^{12}$ Therefore, optimizing nutrition and metabolic response is essential, as patients with severe TBIs who

Table 1: GCS grading of TBI

\begin{tabular}{lc}
\hline GCS & Grading \\
\hline $13-15$ & Mild TBI \\
$9-12$ & Moderate TBI \\
$3-8$ & Severe TBI \\
\hline
\end{tabular}

demonstrate lower nutritional or metabolic response parameters are at elevated risk for poor outcomes. ${ }^{18}$

See Table 2 for MUAC cut-off points for different BMI categories.

\section{Methodology}

This study aimed to describe the factors that affect the nutritional status (malnutrition) of patients with a TBI (all subtypes of TBIs) at Chris Hani Baragwanath Academic Hospital (CHBAH).

This was a prospective observational study. Ethics clearance to perform this study was received from the Human Research Ethics Committee (Medical) at the University of Witwatersrand. It was carried out at CHBAH from 2nd June 2019 to 8th November 2019. A single institution was studied to avoid selection bias and limit the variables in terms of data collection and interpretation.

Patients included in this study were referred and admitted to the Neurosurgical Unit at Chris Hani Baragwanath Academic Hospital. Consent was received either from the patient themselves or from their families. MUAC was measured by the primary author, using the same tape measure, on day 1 (admission day), day 10, and day 21 , on the exact upper arm measurement as before that was documented. Data was entered on Proforma/data collection sheets. The patient's hospital records were used to collect the necessary data needed for this study. A non-contrast CT Brain for each patient was reviewed. This was done on the hospital PACS system.

Data was subsequently reviewed and then analyzed with the help of the University of Witwatersrand Statistical Department.

\section{Statistical Analysis}

- The statistical significance level of all analyzed data was a $p$-value of $<0.001$.

- Continuous variables, for example, age was summarized using mean/median methods depending on the distribution of data.

- Discrete variables, for example, gender, were summarized using either percentages or frequencies.

- Data are described using frequencies, percentages, and charts.

- The paired $t$-test was used to compare the mean MUAC on days 1,10 , and 21.

- The student $t$-test was used to compare the MUAC on days 1, 10, and 21 between other categorical variables.

- The Shapiro-Wilk test was used for the distribution of length of hospital stay and MUAC.

- The Wilcoxon rank-signed test was used to show the decline in MUAC.

\section{Results}

During the study period, 32 patients were included; two patients did not have consent to participate. The majority of our patients were African (97\%), male (97\%), and aged between and 18 and 40 years $(74 \%)$.

Table 2: MUAC cut-off points for different BMI categories

\begin{tabular}{lcc}
\hline \multicolumn{1}{c}{$B M I$ Category } & $B M I\left(\mathrm{~kg} / \mathrm{m}^{2}\right)$ & MUAC cut-off $(\mathrm{cm})$ \\
\hline Severe underweight & $<16$ & $<17$ \\
Underweight & $<18.5$ & $<22.5$ \\
Normal & $18.5-24.9$ & $22.5-27.0$ \\
Overweight & $25.0-29.9$ & $27.1-30.4$ \\
Obese & $30.0-39.9$ & $30.5-37$ \\
Morbidly obese & $>40$ & $>37$ \\
\hline
\end{tabular}


The most frequent mechanism of injury was assault (58\%). A quarter of the patients died $(n=8)$. Treatment was equally distributed between surgery and conservative. Sixty-six percent of the patients received parenteral feeds $(n=21)$.

In this study, $56.25 \%$ of the patients had multiple intracranial injuries, and $43.75 \%$ only had single intracranial injuries. Of the multiple injuries, $25 \%$ only had two intracranial injuries, $18.75 \%$ had three intracranial injuries, and $6.25 \%$ had four and five intracranial injuries, respectively. Approximately $31.25 \%$ of the patients presented with EDH and SAH, 34.75\% with SDH, $28.125 \%$ with contusion and fractures, $25 \%$ with edema, $21.875 \%$ with $\mathrm{ICH}$, and only $6.25 \%$ with pneumocephalus.

The mean length of hospital stay in our sample was 19 days (Standard deviation $=12.4$ ). The Shapiro-Wilk test showed that the length of hospital stay was typically distributed ( $p$-value $=0.230$ ).

The proportion of patients in the normal BMI category significantly increased, while those in the obese group significantly decreased during the first ten days (Fisher's exact test $p$-value $<0.001)$.

MUAC was normally distributed on day 1 and day 10 (Shapiro-Wilk test $p$-value $=0.912$ and 0.840 , respectively) while non-parametric for day 21 (Shapiro-Wilk test $p$-value $=0.045$ ). The mean MUAC lengths were $28.1 \mathrm{~cm}$ (Standard deviation = 2.97) and $27.4 \mathrm{~cm}$ (Standard deviation $=3.1$ ) at day 1 and day 10, respectively. The median MUAC on day 21 was 27.5 (Interquartile range: $25-29.5 \mathrm{~cm}$ ). Results from the paired $t$ test suggest an overwhelmingly significant decrease in MUAC between day 1 and day 10 ( $p$-value $<0.001)$. In addition, there was evidence to suggest that MUAC significantly declined between day 1 and day 21, as shown by the Wilcoxon signed-rank test ( $p$-value $=0.005)$. There was a statistical difference in MUAC between day 10 and day 21 (Wilcoxon signed-rank test $p$-value $=0.465$ ).

Results from the $t$-test showed that patients who were not malnourished (mean $=31$ days) stayed in the hospital significantly longer compared to those who were malnourished (mean $=9$ days), $p$-value $<0.001$. We used Fisher's exact test to assess the association between malnutrition and categorical variables are given the small cell sizes (expected value less than 5 ). In our sample, none of the categorical variables were associated with malnutrition.

See Table 3 for associations between characteristics of participants with malnutrition.

See Fig. 1 for the distribution of MUAC.

Table 3: Association between characteristics of participants with malnutrition $(n=32)$

\begin{tabular}{|c|c|c|c|}
\hline \multirow[t]{2}{*}{ Variable } & \multicolumn{2}{|c|}{ Ever malnourished? } & \multirow[b]{3}{*}{$p$-value } \\
\hline & No & Yes & \\
\hline & $(\mathrm{N}=14)$ & $(\mathrm{N}=18)$ & \\
\hline Length hospital stay & & & $<0.001$ \\
\hline \multirow[t]{2}{*}{ Mean (standard deviation) } & $30.8(8.3)$ & $9.9(5.1)$ & \\
\hline & $\mathrm{N}(\%)$ & $\mathrm{N}(\%)$ & \\
\hline Gender & & & 0.438 \\
\hline Male & $13(92.9)$ & $18(100.0)$ & \\
\hline Female & $1(7.1)$ & $0(0.0)$ & \\
\hline Hospital & & & 0.834 \\
\hline Lenasia & $1(7.1)$ & $1(5.6)$ & \\
\hline Sebokeng & $0(0.0)$ & $2(11.1)$ & \\
\hline TEU & $11(78.6)$ & $12(66.7)$ & \\
\hline TMRH & $2(14.3)$ & $3(16.7)$ & \\
\hline Age group (years) & & & 0.292 \\
\hline $18-30$ & $7(50.0)$ & $4(23.5)$ & \\
\hline $31-40$ & $3(21.4)$ & $9(52.9)$ & \\
\hline $41-50$ & $2(14.3)$ & $2(11.8)$ & \\
\hline $51-60$ & $1(7.1)$ & $0(0.0)$ & \\
\hline$>60$ & $1(7.1)$ & $2(11.8)$ & \\
\hline Race & & & 1.000 \\
\hline African & $14(100.0)$ & $17(94.4)$ & \\
\hline Colored & $0(0.0)$ & $1(5.6)$ & \\
\hline Mechanism of injury & & & 0.608 \\
\hline Assault & $5(62.5)$ & $9(56.3)$ & \\
\hline $\mathrm{FFH}$ & $0(0.0)$ & $2(12.5)$ & \\
\hline GSW & $1(12.5)$ & $0(0.0)$ & \\
\hline MVA & $0(0.0)$ & $1(6.3)$ & \\
\hline MVA / Assault & $1(12.5)$ & $0(0.0)$ & \\
\hline PVA & $1(12.5)$ & $3(18.8)$ & \\
\hline Train accident & $0(0.0)$ & $1(6.3)$ & \\
\hline
\end{tabular}




\begin{tabular}{|c|c|c|c|}
\hline \multirow{2}{*}{ Initial GCS } & \multicolumn{2}{|c|}{ Ever malnourished? } & \multirow{2}{*}{1.000} \\
\hline & & & \\
\hline $13-15$ & $1(7.1)$ & $2(11.1)$ & \\
\hline $9-12$ & $4(28.6)$ & $5(27.8)$ & \\
\hline $3-8$ & $9(64.3)$ & $11(61.1)$ & \\
\hline Modified Marshall Score & & & 0.175 \\
\hline I & $2(14.3)$ & $0(0.0)$ & \\
\hline ॥ & $4(28.6)$ & $5(27.8)$ & \\
\hline III & $3(21.4)$ & $1(5.6)$ & \\
\hline IV & $1(7.1)$ & $1(5.6)$ & \\
\hline V & $4(28.6)$ & $11(61.1)$ & \\
\hline Treatment & & & 0.073 \\
\hline Conservative & $10(71.4)$ & $6(33.3)$ & \\
\hline Surgery & $4(28.6)$ & $12(66.7)$ & \\
\hline Outcome & & & 0.293 \\
\hline Home & $7(50.0)$ & $8(44.4)$ & \\
\hline In-hospital & $2(14.3)$ & $0(0.0)$ & \\
\hline RIP & $2(14.3)$ & $6(33.3)$ & \\
\hline Stepdown & $2(14.3)$ & $4(22.2)$ & \\
\hline Home & $1(7.1)$ & $0(0.0)$ & \\
\hline $\mathrm{D} / \mathrm{C} \mathrm{GCS}$ & & & 0.475 \\
\hline $13-15$ & $10(71.4)$ & $11(61.1)$ & \\
\hline $9-12$ & $2(14.3)$ & $1(5.6)$ & \\
\hline $3-8$ & $2(14.3)$ & $6(33.3)$ & \\
\hline Mode feeds & & & 0.555 \\
\hline Oral & $5(35.7)$ & $5(27.8)$ & \\
\hline Parenteral & $8(57.1)$ & $13(72.2)$ & \\
\hline Parenteral then oral & $1(7.1)$ & $0(0.0)$ & \\
\hline Type Feeds & & & 0.770 \\
\hline FWD & $5(35.7)$ & $5(27.8)$ & \\
\hline Fresubin & $7(50.0)$ & $12(66.7)$ & \\
\hline Low $\mathrm{Na}$ & $1(7.1)$ & $0(0.0)$ & \\
\hline Nutrison & $1(7.1)$ & $1(5.6)$ & \\
\hline Feeds started & & & 0.014 \\
\hline D1 & $4(28.6)$ & $10(55.6)$ & \\
\hline $\mathrm{D} 2$ & $4(28.6)$ & 7 (38.9) & \\
\hline D3 & $6(42.9)$ & $0(0.0)$ & \\
\hline D4 & $0(0.0)$ & $1(5.6)$ & \\
\hline Full feeds & & & 0.241 \\
\hline D1 & $1(7.1)$ & $2(11.8)$ & \\
\hline D2 & $1(7.1)$ & $3(17.6)$ & \\
\hline D3 & $2(14.3)$ & $6(35.3)$ & \\
\hline D4 & $3(21.4)$ & $4(23.5)$ & \\
\hline D5 & $2(14.3)$ & $1(5.9)$ & \\
\hline D6 & $3(21.4)$ & $0(0.0)$ & \\
\hline D7 & $2(14.3)$ & $0(0.0)$ & \\
\hline D8 & $0(0.0)$ & $1(5.9)$ & \\
\hline Multiple/single & & & 1.000 \\
\hline 1 & $6(42.9)$ & $8(44.4)$ & \\
\hline 2 & $8(57.1)$ & $10(55.6)$ & \\
\hline
\end{tabular}


Table 3: Continued

\begin{tabular}{|c|c|c|c|}
\hline Variable & & & \\
\hline Multiple amount & & & 0.971 \\
\hline 1 & $6(42.9)$ & $8(44.4)$ & \\
\hline 2 & $4(28.6)$ & $4(22.2)$ & \\
\hline 3 & $2(14.3)$ & $4(22.2)$ & \\
\hline 4 & $1(7.1)$ & $1(5.6)$ & \\
\hline 5 & $1(7.1)$ & $1(5.6)$ & \\
\hline $\mathrm{EDH}$ & & & 0.446 \\
\hline 1 (not present) & $11(78.6)$ & $11(61.1)$ & \\
\hline 2 (present) & $3(21.4)$ & 7 (38.9) & \\
\hline SDH & & & 0.712 \\
\hline 1 (not present) & $10(71.4)$ & $11(61.1)$ & \\
\hline 2 (present) & $4(28.6)$ & 7 (38.9) & \\
\hline Contusion & & & 1.000 \\
\hline 1 (not present) & $10(71.4)$ & $13(72.2)$ & \\
\hline 2 (present) & $4(28.6)$ & $5(27.8)$ & \\
\hline SAH & & & 0.712 \\
\hline 1 (not present) & $9(64.3)$ & $13(72.2)$ & \\
\hline 2 (present) & $5(35.7)$ & $5(27.8)$ & \\
\hline $\mathrm{ICH}$ & & & 0.703 \\
\hline 1 (not present) & $10(71.4)$ & $14(77.8)$ & \\
\hline 2 (present) & $4(28.6)$ & $4(22.2)$ & \\
\hline Edema & & & 0.252 \\
\hline 1 (not present) & $9(64.3)$ & $15(83.3)$ & \\
\hline 2 (present) & $5(35.7)$ & $3(16.7)$ & \\
\hline Fractures & & & 0.694 \\
\hline 1 (not present) & $11(78.6)$ & $12(66.7)$ & \\
\hline 2 (present) & $3(21.4)$ & $6(33.3)$ & \\
\hline Pneumocephalus & & & 1.000 \\
\hline 1 (not present) & 13 (92.9) & $17(94.4)$ & \\
\hline 2 (present) & $1(7.1)$ & $1(5.6)$ & \\
\hline
\end{tabular}

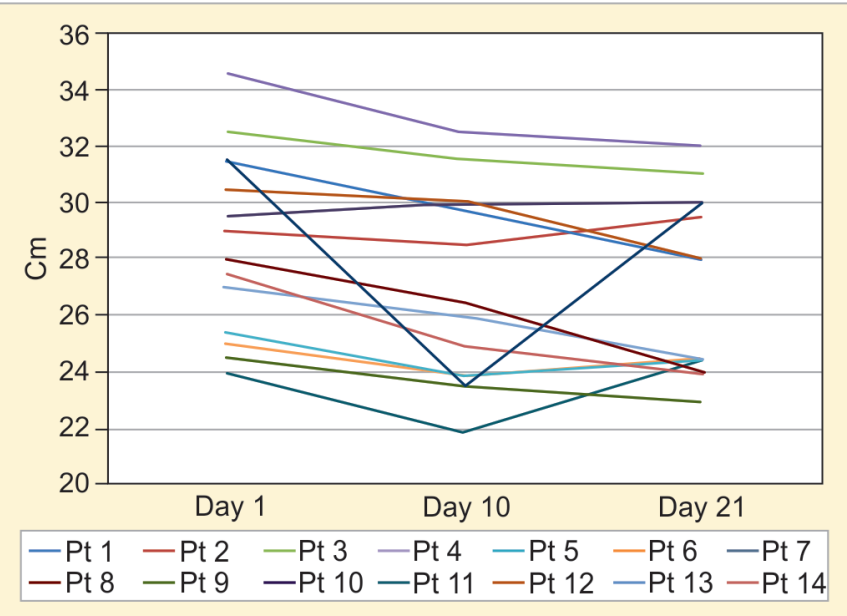

Fig. 1: Distribution of MUAC

\section{Discussion}

To our knowledge, this is the first study conducted in South Africa to analyze the factors that affect nutritional status in post TBI patients.
None of the patients, on admission, fell into the underweight or severe underweight category.

Only 14 patients were still admitted for MUAC measurements on all 3 days.

There is a general decline in MUAC measurements between day 1 and day 10 , of $92.85 \% n=13$. Only 1 patient had an increase in their MUAC, $7.14 \%$. A decline in the MUAC trend does not necessarily mean they moved between BMI categories but lost weight. About $21.42 \%$ of patients dropped a BMl category from obese to overweight, $n=3$, and only $7.14 \%$ from the overweight $\mathrm{BMI}$ category to the normal BMI category, $n=1$. The prevalence of malnutrition on day 10 was $31.25 \%$.

The fact that 18 patients could not complete the three measurements because they were discharged could be attributed to the fact that they were on oral feeds or natural foods; as stated by Caliri et al., a nutritional approach of nutritional intervention integrated with natural foods has contributed to a reduction of recovery time, making the healing path more effective.

The next period of day 10 to day 21 had more unexpected results. The overall prevalence of malnutrition on day 21 was $56.25 \%$. No patient changed BMI categories in this period compared to the $n=4$ patients in the day $1-10$ period. Of the 14 patients who completed all three measurements, $57.14 \%$ 
decreased their MUAC measurement from day $10-21, n=8,35$. $17 \%$ increased their MUAC measurement, $n=5$, and 1 patient had the exact MUAC measurement on day 10 and day $21,7.14 \%$.

The even more significant decrease in MUAC measurement on day 21 contributed to the higher prevalence of malnutrition quoted.

An increase in the MUAC of $35.17 \%$ of the patients can be attributed to nutritional intervention integrated with natural foods, allowing a gradual increase in weight and, subsequently, a better recovery of the lean mass and stabilizing the metabolic, nutritional framework.

In assessing factors associated with malnutrition, a patient was considered malnourished if they were either malnourished on days 10,21 , or both.

\section{LiMitATIONS}

The major limitation of this study was the small sample size, and poor follow-up of the patients included in the study. Statistically significant results could not be achieved.

Serum albumin could also be used as a marker of malnutrition concomitantly with MUAC.

\section{Conclusion}

There is an association with a more extended hospital stay, worse malnutrition, and later feeding. These patients have a worse prognosis and place a heavy burden on the Health Care System. Given these factors, greater care should be taken with early preparation of discharge, if possible. As well as starting feeds as early as possible, aiming for within the first 24 hours after admission, and increasing the rate to the targeted raised basal metabolic rate.

\section{Acknowledgments}

We acknowledge the staff of the Neurosurgery, Trauma, and Dietetics Departments for the ongoing commitment to the care of patients admitted with traumatic brain injuries.

\section{OrCID}

Lauren Ford ${ }^{\circledR}$ https://orcid.org/0000-0003-0067-5879

John Ouma ${ }^{\oplus}$ https://orcid.org/0000-0002-4104-3643

\section{References}

1. Naidoo D. Traumatic brain injury: The South African landscape [Internet]S Afr Med J 2013;103(9):613-614. DOI: 10.7196/ samj.7325.Available from: http://www.samj.org.za/index.php/samj/ article/view/7325/5318

2. Daradkeh G, Essa MM, Samir Al-Adawi S, et al. Nutritional status, assessment, requirements and adequacy of traumatic brain injury patients. Pak J Biol Sci 2014;17(10):1089-1097. DOI: 10.3923/pjbs.2014.1089.1097
3. Helmy A, Vizcaychipi M, Gupta AK. Traumatic brain injury: Intensive care management. Br J Anaesth 2007;99(1):32-42. DOI: 10.1093/bja/aem139

4. Jerome $E$, Laing GL, Bruce $J L$, et al. An audit of traumatic brain injury (TBI) in a busy developing-world trauma service exposes a significant deficit in resources available to manage severe TBI. S Afr Med J 2017;107(7):621-625. DOI: 10.7196/samj.2017. v107i7.10562

5. Corrigan JD, Selassie AW, Orman JA. The epidemiology of traumatic brain injury. J Head Trauma Rehabil 2010;25(2):72-80. DOI: 10.1097/htr.0b013e3181ccc8b4

6. Whois. World Health Organization [Online]. Available from: https:// www.who.int/features/qa/malnutrition/en/ [Accessed 15 April 2019]

7. Cederholm T, Bosaeus I, Barazzoni R, et al. Diagnostic criteria for malnutrition - An ESPEN Consensus Statement. Clin Nutr 2015;34(3):335-340. DOI: 10.1016/j.clnu.2015.03.001

8. Bharadwaj S, Goya S, Tandon P, et al. Malnutrition: laboratory markers vs nutritional assessment. Gastroenterol Rep (Oxf) 2016;4(4):272-280. DOI: 10.1093/gastro/gow013

9. De Souza Campos BBN, MacHado FS. Nutrition therapy in severe head trauma patients. Rev Bras Ter Intensiva 2012;24(1):97-105. DOI: 10.1590/S0103-507X2012000100015

10. Weimann A, Braga M, Carli F, et al. ESPEN guideline: Clinical nutrition in surgery. Clin Nutr 2017;36(3):623-650. DOI: 10.1016/j.clnu.2017.02.013

11. Quirk J. Malnutrition in critically ill patients in intensive care units. $\mathrm{Br}$ J Nurs 2014;9(9):537-541. DOI: 10.12968/bjon.2000.9.9.6287

12. Carney N, Totten AM, Hawryluk GWJ, et al. Guidelines for the management of severe traumatic brain injury 4th edition. Neurosurgery 2017;80(1):6-15.DOI:10.1227/NEU.0000000000001432

13. Dhandapani S, Manju D, Sharma B, et al. Clinical malnutrition in severe traumatic brain injury: factors associated and outcome at 6 months. Indian J Neurotrauma [Internet] 2007:4(1):35-39. Available from: https://www.thieme-connect.com/DOI/DOI?10.1016/S09730508(07)80009-8 DOI: 10.1016/s0973-0508(07)80009-8

14. Chu S-F, Chiu W-T, Binns CW, et al. Early enteral nutrition and clinical outcomes of severe traumatic brain injury patients in acute stage: a multi-center cohort study. J Neurotrauma 2011;29(1):75-80. DOI: $10.1089 /$ neu.2011.1801

15. Sultana T, Karim MN, Ahmed T, et al. Assessment of under nutrition of Bangladeshi adults using anthropometry: can body mass index be replaced by mid-upper-arm-circumference? PLoS One 2015;10(4):e0121456. DOI: 10.1371/journal.pone.0121456

16. Burgos R, Sarto B, Elío I, et al. Prevalence of malnutrition and its etiological factors in hospitals. Nutr Hosp 2012;27(2):469-476. DOI: 10.1590/S0212-16112012000200018

17. Barker LA, Gout BS, Crowe TC. Hospital malnutrition: prevalence, identification and impact on patients and the healthcare system. Int J Environ Res Public Health 2011;2(8):514-527. DOI: 10.3390/ijerph8020514

18. Baltazar GA, Chandrasekhar A. Malnutrition as measured by albumin and prealbumin on admission is associated with poor outcomes after severe traumatic brain Injury. Am Surg [Internet] 2015;81:(2) E61. Available from: https://www.researchgate.net/ publication/271773255 